\title{
On the determination of thermal degradation effects and detection techniques for thermoplastic composites obtained by automatic lamination
}

\author{
M.I. Martín', F. Rodríguez-Lence ${ }^{1}$, A. Güemes ${ }^{2}$, A. Fernández-López², L.A. Pérez- \\ Maqueda $^{3}$, A. Perejón ${ }^{3,4}$ \\ ${ }^{1}$ FIDAMC, Foundation for the Research, Development and Application of Composite \\ Materials, Avda. Rita Levi Montalcini, 29, Tecnogetafe 28906 Getafe (Madrid), Spain; \\ ${ }^{2}$ Departamento de Materiales y Producción Aeroespacial, E.T.S.I. Aeronáutica y del \\ Espacio, Universidad Politécnica de Madrid, Pza. de Cardenal Cisneros 3, 28040 \\ Madrid, Spain;
}

${ }^{3}$ Instituto de Ciencia de Materiales de Sevilla (C.S.I.C. - Universidad de Sevilla). C. Américo Vespucio 49, Sevilla 41092. Spain;

${ }^{4}$ Departamento de Química Inorgánica, Facultad de Química, Universidad de Sevilla, Sevilla 41071, Spain

\begin{abstract}
Automatic lay-up and in-situ consolidation with thermoplastic composite materials is a technology under research for its expected use in the profitable manufacturing of structural aeronautical parts. This study is devoted to analysing the possible effects of thermal degradation produced by this manufacturing technique.

Rheological measurements showed that there is negligible degradation in PEEK for the temperatures reached during the process. Thermogravimetric analysis under linear heating and constant rate conditions show that thermal degradation is a complex process with a number of overlapping steps. A general kinetic equation that describes the degradation of the material with temperature has been proposed and validated. Attenuated total reflectance Fourier transform infrared spectroscopy and X-ray photoelectron spectroscopy confirmed that there is no remarkable degradation. The use of a combination of in-situ and ex-situ experimental techniques, including kinetic modelling, not only provides reliable information about degradation but also allows setting optimal processing conditions.
\end{abstract}

Keywords: Polymer-matrix composites (PMCs); Automated fibre placement (AFP); Process Modeling 


\section{Introduction}

With the goal of industrial application of thermoplastic composite materials in aeronautics, similar techniques to those used with thermosets (automatic tape placement, fibre placement) should be fine-tuned taking into account their demonstrated success in aircraft [1]. Current automatic lamination with thermoplastic composite materials attempts to reach full consolidation in only one-step, avoiding the secondary use of an autoclave. However, the lack of tackiness in the material forces the use of heat sources that apply a punctual or surficial heating that lasts only several seconds.

The operating principle of these machines is the sequential heating of individual layers before being placed in contact with the pre-positioned layer for the production of laminates of different shapes and ply orientations. Different heating sources have been used, with diode laser being a preferred solution [2]. After heating to the melting temperature of the polymer, the layers are compacted by a deformable roller.

Establishing the proper limits for the parameters interacting in the control loop of automatic layup and in-situ consolidation is a complicated task, owing to their coupling. Mathematical models defining the responses of the material to these specific effects are needed. These models depend on the way the specific effects are described, and the property used for their calculation. Diverse effects should be estimated in advance, creating models that contemplate thresholds whilst reaching the required power and speed, for acceptable levels of degradation, crystallization, bonding, and so on [3]. Finally, the control system should implement all of them, giving proper impact ranges and estimating the degree of deviation from the ideal result.

Owing to the elevated requirements imposed by aeronautics, high-performance thermoplastics such as those in the poly-aryl-ether-ketone (PAEK) family are the focus of most of the lamination endeavours to set up this manufacturing technology [4-9], with the exception of some works devoted to the application of PPS (poly- phenylene-sulphide) [5,10,11], PEI ( polyetherimide) [12], and current works with PA (polyamide) [13,14]. Poly-ether-ether-ketone (PEEK) is a linear, aromatic, semi-crystalline thermoplastic polymer with excellent thermal stability, chemical resistance, and mechanical properties. Its glass transition temperature appears at around $416 \mathrm{~K}$ and its melting point is $616 \mathrm{~K}$. Moreover, above $723 \mathrm{~K}$, 4-phenoxyphenol and 1,4diphenoxybenzene are detected, showing chain scission thermal degradation [15]. Other authors suggest that the degradation produces cross-linking in the matrix structure, especially under an oxidative atmosphere, which affects the viscosity and the ability to crystallize [16,17]. The atmosphere has an important effect on the degradation, with differences in the time required for degradation at the same temperature as high as $16 \%$ in either inert or oxidative atmospheres [18].

For the automatic lamination processes of carbon fibre/PEEK composites (CF/PEEK), temperatures in the range from $623 \mathrm{~K}$ to $673 \mathrm{~K}$, or even higher, should be applied to achieve melting and bonding among layers. Thus, the processing temperature is very close to the onset of degradation [18]. Moreover, considering that the temperature control is manual, instances of overheating could discretely appear, thereby changing the material elementary structure.

Considering the normal trends in automatic lamination with carbon fibre-reinforced thermoplastics, the relevant speeds of lamination differ from consulted groups of study. As a parameter still under analysis, it is possible to find values as low as $10 \mathrm{~mm} / \mathrm{s}$ [19] and as high as $400 \mathrm{~mm} / \mathrm{s}$ [20], which imply times of maximum temperature stabilization in the range of seconds, 
depending on the heating spot. Additionally, there is an important effect of polymer molecular weight, which affects the capacity of chains to move and, therefore, the maintenance time needed to reach full healing. Thus, for the sake of establishing comparisons, all these parameters should be carefully considered. Owing to the fact that thermal degradation is not only affected by temperature but, also by the dwell time at this temperature, both parameters should be considered in any degradation model. For a proper kinetic model, a specific monitoring parameter (mass loss, linkage $\%$ content, molecular weight, or viscosity) should be considered.

Degradation kinetics permit one to obtain a mathematical formula that relates the extension of conversion (degradation by means of different parameters) to time-temperature profiles. Kinetic thermal analysis is a powerful tool, which is widely employed to estimate in advance the behaviour of a material subjected to a specific thermal process condition. It is a valuable tool in many scientific branches and has already been used with PEEK $[15,21,22]$.

In particular, for the PAEK family, several studies have tried to obtain information about the degradation mechanisms. Most of them focused on the detection and explanation of the degradation mechanism from a physical-chemical point of view [16,23-26] and a low number of works elucidate the kinetic model. Some of them, related to kinetics, are focused on pyrolytic tests [27], oxidative atmosphere tests [28], or both. In the particular case of oxidative degradation, the authors consider that there are only two mechanisms interacting from the beginning $(0 \%$ mass loss) to the end (100\% mass loss). Nevertheless, the great dispersion observed in activation energies, even for the first $30 \%$ of mass loss, suggests the presence of more than one mechanism in this small range.

Furthermore, there are many works reporting that, before the appearance of any kind of measurable degradation by mass loss, PEEK already experiences modifications that affect its structure. This effect is related to the unstable behaviour of ether and carbonyl groups, which is mainly detectable by rheological testing and by appreciable changes in the crystallization behaviour [17,29]. Other authors consider that mass loss fails when one tries to associate its appearance with detrimental mechanical properties [30].

This study aims to analyse several effects in PEEK degradation and CF/PEEK composites. It includes different experimental measurements for the determination of possible degradation effects after diode-laser-irradiation processing of the composite material. Moreover, a simplified kinetic equation is proposed that predicts the behaviour of neat resin under any heating profile by considering two monitoring parameters independently: mass loss and viscosity changes.

\section{Theoretical background of thermal degradation kinetics}

Equation 1 is commonly used for studying the kinetics of solid-state reactions [31]:

$$
\frac{d \alpha}{d t}=A \exp \left(\frac{-E_{a}}{R T}\right) f(\alpha)
$$

where $A$ is the pre-exponential Arrhenius factor, $E_{a}$ the activation energy, $\alpha$ the reacted fraction or conversion, $\mathrm{d} \alpha / \mathrm{d} t$ the reaction rate, and $f(\alpha)$ the kinetic model.

This equation can be rewritten considering the evolution of conversion with temperature instead of its time dependency, by means of the reaction rate, $\beta$. 


$$
\frac{d \alpha}{d T}=\frac{A}{\beta} \exp \left(\frac{-E_{a}}{R T}\right) f(\alpha)
$$

118 From Equation 2, it follows that it is necessary to obtain the values of the kinetic triplet $\left(A, E_{a}\right.$, $119 f(\alpha))$ in order to complete the information that properly describes the kinetics of a reaction.

120 The use of the so-called 'isoconversional' methods facilitates this task, because the reaction rate 121 at a constant extent of conversion is considered to be only a function of temperature. Thus, the activation energy values can be extracted without any consideration of the reaction model. One of the most used differential isocoversional methods is that of Friedman [31], which for nonisothermal heating programs, has the form (3):

$$
\ln \left[\beta_{i}\left(\frac{d \alpha}{d T}\right)_{\alpha, i}\right]=\ln \left[\left(f(\alpha) A_{\alpha}\right]-\frac{E_{\alpha}}{R T_{\alpha, i}}\right.
$$

125

127

128

129

130

131

132

133

134

135

136

137

138

139

140

141

142

143

144

145

The index ' $i$ ' represents each of the set of dynamic heating programs used for the analysis. The left-hand side of the equation is plotted against $\frac{1}{R T_{i}}$; the plot consists of straight lines linked to each conversion value and with a number of points that depends on the number of heating programs used. The slope of the lines gives the value of the activation energy $E_{\alpha}$.

Polymer thermal degradation is usually described by complex mechanisms depending on the number of reactions implied [32]. The presence of multiple reactions complicates the application of isoconversional methods in order to obtain the activation energy, whose evolution is highly dependent on conversion. For this reason, it is not realistic to determine the corresponding activation energy values for each stage using the isoconversional methodology. It is important to clarify that the interaction of simple individual mechanisms is not certified by the fact that a constant activation energy with respect to conversion was obtained, because in any case, a deeper analysis is needed [33].

Attempting to overcome the difficulties when more than one stage is involved in the overall process, several solutions have been suggested. One of these solutions considers the deconvolution of the experimental curves of the reaction rate $\left(\frac{d \alpha}{d t}\right)$ into different subcurves that represent each stage individually [34,35]. This methodology is applied in the present work in an attempt to obtain the equation that describes the thermal degradation of PEEK.

Thus, after deconvoluting the experimental curves for each heating rate, they are analysed independently for each degradation stage [36]. The calculus of the kinetic triplet is based on the combined kinetic analysis method [37]. For the combined kinetic analysis methodology, the general kinetic equation is converted into the linear form shown in Equation 4:

$$
\ln \left[\frac{d \alpha}{d t} \frac{1}{f(\alpha)}\right]=\ln (c A)-\frac{E}{R T}
$$

146 However, the plot of the left-hand side of this equation versus the inverse of the temperature yields 147 a straight line only if the correct kinetic function, $f(\alpha)$ is considered. Moreover, the proposed 148 kinetic functions are idealized physical models that may not be useful for all the solid-state 149 reactions, in which factors such as the particle size, the particle shape, etc. have an important 150 influence on the reaction mechanism. It has been demonstrated that this limitations can be 151 overcome if the modified Sestak-Berggren equation is considered as $f(\alpha)$ : 


$$
f(\alpha)=\alpha^{m}(1-\alpha)^{n}
$$

Thus, it has been shown that this expression fits all $f(\alpha)$ corresponding to the ideal kinetic models proposed in the literature and even their deviations from the ideal conditions [38]=, by adjusting the parameters c, $\mathrm{n}$ and $\mathrm{m}$. Equivalent reduced Sestak-Berggren equations for each ideal kinetic model have been proposed [38]. Substituting equation (5) into equation (4) the general kinetic expression for the combined kinetic analysis method is obtained:

$$
\ln \left[\frac{d \alpha}{d t} \frac{1}{\alpha^{m}(1-\alpha)^{n}}\right]=\ln (c A)-\frac{E}{R T}
$$

The kinetic triplet is obtained by plotting the left-hand side of Equation 6 against reciprocal temperature, independently for all the experimental data corresponding to each degradation stage. From the values of $n$ and $m$ that give the best linearity fit, the kinetic model followed by each decomposition stage is obtained. The linearity is evaluated by the coefficient of linear correlation. Afterwards, the values of the activation energy and pre-exponential factor are obtained from the slope and the intercept of the straight line. Normal ranges of $\alpha$ considered for optimisation are $0.1-0.9$ or $0.05-0.95$ in order to avoid experimental errors that are more relevant for low and high values of $\alpha[37,39]$.

\section{Experimental}

\subsection{Materials}

To study the thermal degradation process experienced by the carbon fibre/thermoplastic material used in automatic lamination and in-situ consolidation manufacturing processes, tests have been conducted on a neat PEEK resin (without treatment) and the CF/PEEK composite material. Thus, two different materials have been used in this study, neat polymer PEEK 450G Victrex in pellet form and APC2/AS4 Solvay pre-impregnated PEEK/long carbon fibre material, with fibre content close to $60 \%$ in volume.

Both materials were tested as received by the supplier (without any treatment) and after being processed by a specific manufacturing technique. The studied samples were classified as shown in Table 1 for the sake of clarity. The neat PEEK resin was studied as received (sample C1) and after reaching $2 \%$ degradation (sample $\mathrm{C} 2$ ). In the latter case, the sample was heated in the thermogravimetric analysis (TGA) apparatus up to the point when the degradation, measured as the mass loss, reached $2 \%$; it was then quenched to room temperature $(\sim 298 K)$. For the preimpregnated material, it was studied as received (sample C3) and after laser irradiation treatment (samples C4 and C5). Diode-laser-irradiated samples were prepared using a gantry style machine developed by MTorres (Pamplona, Spain) using a $500 \mathrm{~N}$ compaction force and a speed of $1 \mathrm{~mm}$ $\min ^{-1}$. An operator, based on noncontact indications given by thermographic camera, controlled the applied power supplied by a $500 \mathrm{~W}$ laser with a wave length of $980 \mathrm{~nm}$. Sample C4 was irradiated with low energy (normal operation conditions) that induces a sample temperature in the range of 623-673 K, whereas sample C5 was irradiated with higher energy (over-irradiation conditions) inducing a higher sample temperature, in the range of $673-723 \mathrm{~K}$. 


\begin{tabular}{|l|l|}
\hline MATERIAL & CODE \\
\hline PEEK 450G AS RECEIVED & $\mathrm{C} 1$ \\
\hline PEEK 450G AFTER REACHING 2\% OF DEGRADATION BY TGA & $\mathrm{C} 2^{*}$ \\
\hline APC2/AS4 AS RECEIVED & \\
\hline $\begin{array}{l}\text { APC2/AS4 INDIVIDUAL LAYER AFTER LASER IRRADIATION. } \\
\text { Temperature: 623-673 K, Force: } 500 \text { N, Speed: } 1 \text { m min }{ }^{-1}\end{array}$ & $\mathrm{C} 3$ \\
\hline $\begin{array}{l}\text { APC2/AS4 INDIVIDUAL LAYER AFTER LASER IRRADIATION } \\
\text { Temperature: } 673-723 \mathrm{~K}, \text { Force: } 500 \mathrm{~N} \text {, Speed: } 1 \mathrm{~m} \mathrm{~min}^{-1}\end{array}$ & $\mathrm{C}{ }^{*}$ \\
\hline *Cycled before testing & \\
\hline
\end{tabular}

\subsection{Characterisation techniques}

Several samples were analysed by attenuated total reflection Fourier transform infrared spectroscopy (ATR-FTIR) using a Nicolet iN10/Nicolet iZ10 instrument from Thermo Scientific. The results have been normalised by using the band at $1592 \mathrm{~cm}^{-1}$ as a reference.

The experiments were carried out on the TGA residual coded as $\mathrm{C} 2 *$ and over small square samples of around $15 \times 15 \mathrm{~mm}$ of unidirectional carbon fibre/PEEK (APC2/AS4), in transversal direction to the fibre.

For X-ray photoelectron spectroscopy (XPS), a SPECS GmbH with a UHV system, and a PHOIBOS 150 9MCD as an energy analyser with nonmonochromatic magnesium source (200 $\mathrm{W}-12 \mathrm{kV}$ ) were used.

Tests were conducted over small square samples of around $15 \times 15 \mathrm{~mm}$ of unidirectional carbon fibre/PEEK (APC2/AS4) in transversal direction to the fibre.

The TGA tests were conducted with a calibrated TGA Q500 from TA Instruments using $5 \mathrm{mg}$ samples (corresponding to the half of one pellet). The tests were conducted in an airflow of 90 $\mathrm{ml} / \mathrm{min}$ to simulate conditions in the lamination machine that works in a noncontrolled static air atmosphere. 


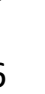

The experiments were performed both using conventional linear heating conditions and constant rate thermal analysis (CRTA). CRTA provides more resolution power for overlapping processes and more discrimination power for discerning the kinetic model [40]. The foundation of this methodology is maintaining the reaction rate at a desired value using a control system that regulates the furnace temperature. It has been demonstrated that the shape of the $\alpha-T$ curves obtained by CRTA allows elucidating the kinetic model followed by the process [41-43].

The evolution of conversion was extracted from equation (7) by subtracting the weight percentage measured at different times $\left(W_{t}\right)$ during the experiment to the initial weight percentage ( $W_{0} \sim 100 \%$ ), and dividing this quantity by the final relation between the weight percentage at the beginning $\left(W_{0} \sim 100 \%\right)$ and at the end of the test $\left(W_{t}\right)$.

$$
\alpha=\frac{W_{0}-W_{t}}{W_{0}-W_{f}}
$$

\section{- Rheology}

Following the methodology described in the literature, six experiments were conducted with a parallel plate rheometer AR-G2 from TA Instruments with aluminium disposable plates of $25 \mathrm{~mm}$ in diameter, at $653,673,693,713,733$, and $753 \mathrm{~K}$. The tests were performed with a frequency of $0.2 \mathrm{~Hz}$ and a strain of $0.2 \%$ over PEEK $450 \mathrm{G}$ Victrex (C1), trying to obtain similar gap dimensions for all the samples tested (approximately $1000 \mu \mathrm{m}$ ). The material was placed in the rheometer in the shape of pellets, mass quantity was variable attempting to obtain meniscus and similar values for gap.

\section{Results and discussion}

In order to understand the possible thermal degradation experienced by the carbon fibre/thermoplastic material during the lamination and in-situ consolidation manufacturing process using laser treatment, several strategies have been used. In general, the main degradation effects for oxidative degradation of polymeric materials are described in literature as chainscission or cross-linking [44]. Some of these degradation phenomena involve mass loss, which could be detected by thermogravimetric methods, whereas others evolve without any mass loss $[17,45,46]$. In this latter case, rheology measurements or differential scanning calorimetry (DSC) are suitable methods for detecting the effects of degradation. In the case of DSC, the effects are shown on melting and crystallisation, mainly by a delay in crystallisation and in the dimensions of obtained crystal structures [47]. However, in a previous work it was affirmed that for PEEK, DSC is not sensitive enough for characterising the first stages of degradation [46]. On the other hand, rheological properties, such as complex viscosity, are quite sensitive to chain modifications (scission, branching, cross-linking) and are suitable parameters for monitoring thermal degradation [47-49].

In this work, rheology was used to detect first stages of degradation in the temperature range of $623-723 \mathrm{~K}$ using the data from the first $100 \mathrm{~s}$. Figure 1 shows the evolution of complex viscosity 
with time for different isothermal programs, as obtained in oscillatory tests for a PEEK sample (C1).

The information obtained from the experiments was processed using the reticulation model described in [17,50] and also applied in [29]. The model is based on considering the number of chains at the beginning of the test and their evolution with time under a specific thermal program, and relating them with the molecular weight and complex viscosity of the polymer. Thus, the number of chains is calculated by using the reverse of average molecular weight after being converted to weight average molecular weight considering polydispersity indexes (under the hypothesis of a small variation in polydispersity during degradation, these indexes remain constant). The molecular weight in mass is directly linked to the complex viscosity under the hypothesis of linear polymer. At this point, a relationship between the evolution of reticulation acts and complex viscosity is determined by means of different isothermal programs. The complex viscosity exhibits a linear tendency with time at the beginning of the tests, which changes at longer times. Considering that in-situ consolidation implies short heating times, the linear tendency can be considered for the goal pursued in this study. The slope of the line when complex viscosity tends to zero, is related to the apparent reticulation speed which follows an Arrhenius law with temperature. The reticulation acts (Figure 2) are extracted by multiplying the apparent reticulation speed by the time, as shown in Equation 8.

The polydispersity and average molecular weight for PEEK, needed for the calculus, were taken from [17]. In the present study, the values calculated for the apparent activation energy in the reticulation phenomenon ( $E_{\text {reticulation }}$ ) and pre-exponential factor $(A)$ resulted into be $84.64 \mathrm{~kJ} / \mathrm{mol}$ and $7.91 \cdot 10^{-3} \mathrm{~mol} \cdot \mathrm{g}^{-1} \cdot \mathrm{s}^{-1}$, respectively. The value obtained for $E_{\text {reticulation }}$ is of the same order of magnitude as those referred to in [17,50], taking into account the differences due to the execution under different atmospheres.

Applying this method to a typical profile in automatic lamination and in-situ consolidation (fast increase to the targeted temperature and stabilisation over several seconds) a very low number of reticulation acts (' $n$ ') are obtained, which suggests that although degradation by cross-linking occurs, it could be considered as negligible. It is important to take into account that with this manufacturing process, the sample is re-heated again after each laser passing step, and thus the final value of cross-linking for one layer increases and depends on the number of layers.

$$
n(T, t)=\text { Apparent reticulation speed } \cdot t=A \exp \left(-\frac{E_{\text {reticulation }}}{R T}\right) t
$$

Another approach for studying the thermal degradation of PEEK is TGA. In this case, the mass loss, as a consequence of chain scissions that yield smaller subunits which eventually volatise, is recorded as a function of time and temperature. Different heating schedules have been proposed in literature, with linear heating being the most conventional schedule used. In this case, the temperature is linearly increased with time while the mass change of the sample is recorded. A different approach is sample-controlled thermal analyses, of which CRTA is the most used. In a CRTA experiment, the temperature is controlled in such a manner that the reaction rate is kept constant during the entire process. Thus, the change in mass is used for monitoring the process as it is used as an experimental signal proportional to the reaction rate. CRTA tests have much higher resolution power for overlapping processes than conventional linear heating [35,51,52].

Figure 3 shows the results of a CRTA test conducted in air on neat resin PEEK 450G Victrex (C1) using a selected constant reaction rate of $0.004 \mathrm{~min}^{-1}$. Figure $3 \mathrm{a}$ shows the evolution of 
conversion and temperature as a function of time. It is clear that the reaction fraction describes a straight line with a slope of $0.004 \mathrm{~min}^{-1}$ as programmed, whereas the evolution of the temperature is complex and it is determined by the evolution of the process itself. The multistep nature of the degradation with overlapping stages is quite clear in both Fig. $3 \mathrm{a}$ and Fig. $3 \mathrm{~b}$ (the latter figure includes the evolution of the reaction fraction with the temperature). Our analysis will focus on the first steps of the thermal degradation, as they are the most significant from the processing point of view. Thus, three stages for PEEK degradation up to $\alpha=0.30$ (30\% mass loss) are discriminated in Figure 3. The ends of these stages have been pointed out with numbers 1, 2, and 3 in Fig. 3b. There is a first step that covers the range of $\alpha$ from 0 to 0.02 . After this first step, there is an inflexion point in the curve. This feature is quite characteristic of nucleation and growth kinetic mechanisms or of random scission [53]. This second step seems to end at $\alpha=0.08$, where there is change in the curve indicating the beginning of the third stage that continues up to a value of $\alpha \sim 0.3$.

Figure 4 presents the $\alpha-T$ curves and the corresponding $\mathrm{d} \alpha / \mathrm{d} t$ curves versus temperature for the thermal degradation of PEEK in air at four different linear heating rates, reaching the stage of complete degradation (zero residual, $W_{t}=0$.) of the sample in all cases. It is clear from this figure that the process is complex, since multiple steps of degradation are obtained, as anticipated by the CRTA analysis in Fig. 3. Moreover, the curves are shifted to higher temperatures with the increasing heating rate, which indicates that the thermal degradation of PEEK is a process controlled by the kinetics.

Based on these observations, a deconvolution of the curves was performed to obtain the individual stages of PEEK degradation. This methodology was applied to the first three stages that correspond to a mass degradation percentage of $30 \%(\alpha=0.3)$, which is more than enough to consider a detrimental effect in the polymer. The three resulting individual peaks were used for the subsequent kinetic analysis. The deconvolution of the peaks was carried out by using the software Fityk and the Fraser-Suzuki equation, as recommended for working with kinetic curves because they are asymmetric [34,54]. The deconvolution for the experiment at $10 \mathrm{~K} / \mathrm{min}$ is included in Fig. 5 as an example of the work carried out. The deconvolution was performed in the entire $\alpha$ range, but only the three first peaks were used for the subsequent kinetic analysis, as mentioned above. The set of curves corresponding to the three first degradation stages for the different heating rates are plotted in Figure 6; the three kinetic triplets corresponding to the three different degradation stages were obtained from the three sets of curves.

The contribution of each stage to the overall degradation process was determined from the area under the $\frac{d \alpha}{d t}-T$ peaks, and it was observed that they remain constant, independently of the heating rate, with values of: $2 \%$ (first stage), $6 \%$ (second stage), and 22\% (third stage), in agreement with the contributions estimated by CRTA, which suggests that the three stages are independent [33]. Therefore, their activation energies should not depend on conversion and the application of the isoconversional method is justified.

The Friedman isoconversional method was applied to each of the three stages. The method relies on the plot of the left-hand side of the Friedman equation (3) against reciprocal temperature for the different heating programs used over a specific range of conversion values. The slope of each of the straight lines obtained gives the value of the activation energies of degradation of PEEK, which remains almost constant over the whole range of conversion and for each stage of degradation, as shown in Figure 7. Other authors obtained an overall activation energy of 236.8 
$\mathrm{kJ} / \mathrm{mol}$ for the thermal degradation of PEEK in air [55], a value which is close to those obtained in this work for the first and third stages. However, they simplified the process by considering only two stages up to $100 \%$ of degradation, associated with the two main peaks visible in Fig. $5 \mathrm{~b}$, and without taking into consideration that the process is much more complex, as it has been shown here.

Subsequently, the combined kinetic analysis described in Section 2 was employed to extract the kinetic triplets for each degradation stage of PEEK, using an optimisation code created with Mathcad software. The results are summarised in Table 3. The plot of the straight lines obtained after optimisation are included in Figure 8. The good fitting attained suggests that the deconvolution from the experimental curves was done properly.

Table 2 Kinetic parameters obtained for the three first decomposition stages of PEEK 450G Victrex (C1).

\begin{tabular}{|c|c|c|c|c|c|c|}
\hline $\begin{array}{c}\text { Process } \\
(\text { Peak })\end{array}$ & $\begin{array}{c}\text { Contribution } \\
(\%)\end{array}$ & $\begin{array}{c}\text { Pre-exponential } \\
\text { factor }(c A) \\
{[1 / \mathrm{min}]}\end{array}$ & $\begin{array}{c}\text { Activation } \\
\text { Energy } \\
\left(E_{a}\right) \\
{[\mathrm{kJ} / \mathrm{mol}]}\end{array}$ & $\begin{array}{c}\alpha \\
\text { range }\end{array}$ & $n$ & $m$ \\
\hline $1^{\text {st }}$ & 2 & $2.610^{15} \pm 3.610^{14}$ & $242.9 \pm 0.9$ & $0.01-0.99$ & 1.215 & 0.201 \\
\hline $2^{\text {nd }}$ & 6 & $6.910^{11} \pm 8.110^{10}$ & $188.1 \pm 0.8$ & $0.01-0.99$ & 0.940 & 0.720 \\
\hline $3^{\text {rd }}$ & 24 & $8.010^{14} \pm 8.610^{13}$ & $241.7 \pm 0.8$ & $0.01-0.99$ & 0.939 & 0.677 \\
\hline
\end{tabular}

The values of $n$ and $m$ determine the reaction mechanism or kinetic model obeyed for each stage; using the values obtained for $n$ and $m$, a comparative plot was prepared attempting to determine similarities with the theoretical models. As can be observed in Fig. 9, the first stage of degradation overlaps the F1 theoretical curve in most of the range of conversion, whilst the second and third stages generate a curve that is almost identical to the corresponding A2 mechanism. Interestingly, the CRTA curve showed for the second and third stages the characteristic shape of a nucleation and growth mechanism, as A2.

Taking into account the above results, the equation for the thermal degradation of PEEK 450G in air, based on the thermogravimetric measurements, can be represented as follows:

$$
\begin{aligned}
\frac{d \alpha}{d t}=0.02(2.6 & \left.10^{15} \exp \left(\frac{-242.910^{3}}{R T}\right)\left(\alpha^{0.201}(1-\alpha)^{1.215}\right)\right) \\
& +0.06\left(6.910^{11} \exp \left(\frac{-19110^{3}}{R T}\right)\left(\alpha^{0.720}(1-\alpha)^{0.940}\right)\right) \\
& +0.24\left(8.010^{14} \exp \left(\frac{-241.710^{3}}{R T}\right)\left(\alpha^{0.677}(1-\alpha)^{0.939}\right)\right)
\end{aligned}
$$

The reliability of this equation was verified by performing its numerical integration in the $\alpha$ range considered (using Runge-Kutta 4 as the resolution method), and the result was compared to the $\alpha-T$ experimental curves. Figure 10 presents the comparison with the experimental curve recorded 
at $10 \mathrm{~K} / \mathrm{min}$. A nearly perfect match up to $30 \%$ of degradation is obtained between the simulated and the experimental curves, which indicates that the deconvolution and the kinetic triplets obtained for each degradation stage of PEEK in air are reliable. A small deviation between the simulation and the experimental curve is observed for conversions close to 0.3 , probably due to the influence of the next degradation stages $(\alpha>0.3)$. It is important to remark that these results were obtained without any assumptions regarding the kinetic models followed by the stages involved in PEEK degradation in air.

The kinetic equation 9 was also integrated in the decomposition range under study $(0 \leq \alpha \leq 0.3)$, for predicting the degradation of PEEK under the particular conditions of automatic lay-up and in-situ consolidation, and for conditions under which higher temperatures are reached. It was considered that the material experiences isothermal profiles that last for $5 \mathrm{~s}$. Figure 11 shows the results of the numerical integration for isotherms at temperatures ranging from $673 \mathrm{~K}$ (operating conditions) to $1073 \mathrm{~K}$. As it may be seen, at $1073 \mathrm{~K}, 30 \%$ of degradation (meaning $9 \%$ in the sample because here reaching $100 \%$ of degradation means a real $30 \%$ in the sample) is achieved in only $0.2 \mathrm{~s}$, whereas at $973 \mathrm{~K}$ and $923 \mathrm{~K}$, this degradation value is obtained after $2.8 \mathrm{~s}$ and beyond $5 \mathrm{~s}$, respectively. Interestingly, the degradation at $873 \mathrm{~K}$ and below this temperature can be considered negligible for a $5 \mathrm{~s}$ isotherm (Fig. 11b). Therefore, the kinetic model predicts that the samples do not suffer any mass loss under the conditions of automatic lay-up and in-situ consolidation. To further validate these predictions, samples subjected to either conventional thermal degradation or laser treatment were investigated by other ex-situ experimental techniques, namely FTIR and XPS

It has been shown that FTIR is a useful technique for the characterisation of thermal degradation of PEEK samples [56]. Moreover, it could be useful to determine the effect of laser irradiation in the modification of the structure of polymeric materials [57]. Samples of PEEK 450G Victrex were analysed as received (sample $\mathrm{C} 1$ ) and compared to a PEEK sample obtained after reaching $2 \%$ of mass loss by TGA (sample C2). The ATR-FTIR tests are shown in Figure 12 . These spectra are used as a reference to understand possible degradation mechanisms appearing in the material. The results show the following tendencies [58]: (i) appearance of one peak at $1714 \mathrm{~cm}^{-1}$, related to the scission of ketone adjacent bonds and reduction of phenyl's conjugated double bond, (ii) decreasing in 1486, 1304, and $1010 \mathrm{~cm}^{-1}$ peaks associated with effects on phenyl group (this effect is also confirmed by the increase in nonaromatic hydrogen related to peaks in the range 2800 $3000 \mathrm{~cm}^{-1}$ ), (iii) disappearance of $1276 \mathrm{~cm}^{-1}$ peak related to scission of ether groups, the same effect is also related to the decrease in $1215 \mathrm{~cm}^{-1}, 1184$, and $1156 \mathrm{~cm}^{-1}$, (iv) peaks at 926,836 , and $680 \mathrm{~cm}^{-1}$ decrease as well, which could be related to the reduction of aromatic hydrogen. The results are in good agreement with $[45,59]$.

For the composite material APC2/AS4 Solvay, three different samples were tested: one corresponding to the material as received (C3) and two corresponding to irradiated samples with lower (C4) and higher (C5) laser energies that induce different processing temperatures, as shown in Table 1. The main observable effects, before and after laser irradiation (in normal operative conditions, C4, and over-irradiated, C5) are shown in Figure 13. Very small changes are observed among the spectra corresponding to the three samples. Thus, only small modification of the shoulder at $1253 \mathrm{~cm}^{-1}$ (related to ether bonds) and changes in the nonaromatic hydrogen bonds are observed. Therefore, the variations are too small to ensure that they are related to some specific modification in the material structure. Considering these results, it could be concluded that of the two laser treatments performed in this work, the normal and high power, neither produced any 
significant degradation detectable by ATR-FTIR, in agreement with predictions made from the

412 kinetic parameters calculated by the combined kinetic analysis (equation 9 and figure 11).

XPS was applied to samples of a pre-impregnated material (APC2/AS4) as received from the supplier (C3) and after laser normal irradiation (C4). This technique is widely used to characterise samples after specific treatments, with surficial modification for improving adhesion being one of the most frequently used methodologies $[45,46,60]$. The main difference between this technique and ATR-FTIR is the depth under analysis; in the case of XPS, this in the nanometre range. The results obtained were processed by using the software package OriginPro 8.6. The main information was extracted from the band of binding energies corresponding to C1s after applying deconvolution by using Fityk software and Gaussian functions (the O1s information was discarded owing to the ambiguity of fitting) [60]. With the objective of determining a possible interaction of chain scission related to ether or ketone bonds, a comparison among the area of deconvoluted peaks and the general area of $\mathrm{C} 1 \mathrm{~s}$, reveals that the irradiated sample has experienced an increase in aromatic carbon bonds $(2.1 \%)$, decreases in ether $(1.6 \%)$ and ketone $(0.53 \%)$ carbon bonds, and no effect on alkene bonds (Figure 14). These results could in principle be associated to an oxidative effect after automatic lay-up and in-situ consolidation. However, the differences are too small to be considered a clear consequence of degradation and could be related to experimental deviations. Thus, XPS results also seem to validate the predictions from the kinetics analysis that indicated negligible decomposition under the laser irradiation processing conditions.

\section{Conclusions}

The thermal degradation of PEEK in air was studied under in-situ heating conditions by means of rheological and thermogravimetric measurements. The variation in complex viscosity was used as a degradation monitoring parameter for in situ measurements at a constant temperature. Only for the maximum studied temperature, $753 \mathrm{~K}$, a significant increase in cross-linkage was observed after a long induction period, whereas for lower temperatures, the increase in cross-linkage was quite small, indicating negligible degradation. Thermogravimetric studies under both linear heating and CRTA conditions showed that the degradation in air is a very complex process with three overlapping steps up to $30 \%$ of mass loss. A complete kinetic description of this initial degradation range was performed using updated deconvolution procedures and the Combined Kinetic Analysis. From the analysis, a general equation that describes the degradation rate as a function of temperature was proposed. This kinetic equation allows simulating the experimental curves used in the analysis and making predictions under different heating conditions. Thus, the thermal behaviour of the material during the heating conditions reached during laser irradiation in the lay-up and in-situ consolidation was simulated. The model predicted negligible degradation under these conditions. Ex-situ studies by ATR-FTIR and XPS confirmed that carbon fibrePEEK composites subjected to this processing technique do not suffer significant degradation. Therefore, by a combination of experimental measurements and kinetic simulation, the optimum processing conditions for lay-up and in-situ consolidation of carbon fibre-PEEK composites could be established. 
456 The authors of this paper want to acknowledge Airbus Group and the government of the 457 Community of Madrid for their financial support to the research and development projects.

458 Financial support from Contracts CTQ2014-52763-C2 and CTQ2017-83602-C2 (MINECO-

459 FEDER) is acknowledged. AP thanks VPPI-US for his current contract.

460

461

462

463

464

465

466

467

468

469

470

471

472

473 


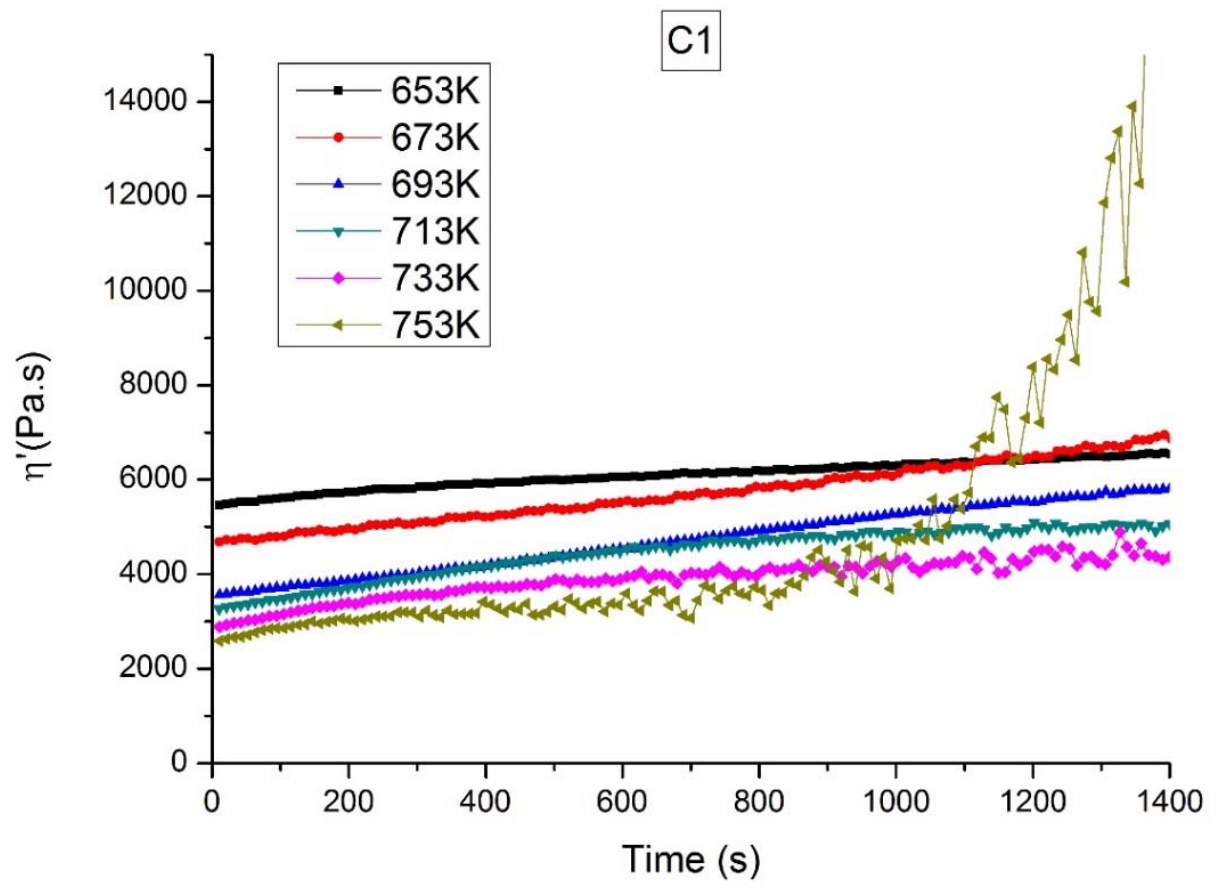

474

475

476

477

478
Figure 1. Evolution of complex viscosity with time for different isothermal conditions over PEEK $450 \mathrm{G}$ and under oxidative atmosphere - Rheological oscillatory tests. (For interpretation of the references to colour in this figure, the reader is referred to the web version of this article)

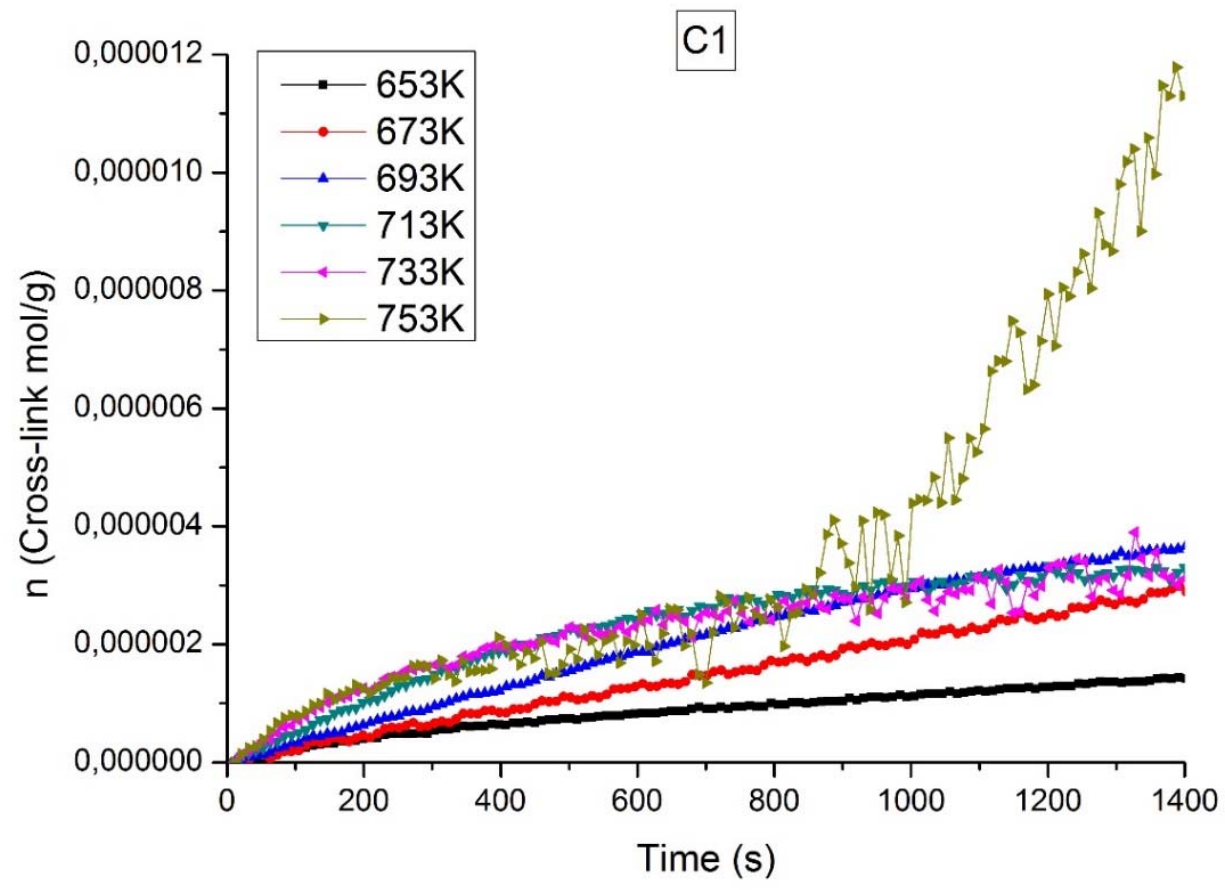

Figure 2. Cross-linking obtained by eq. 5 based on rheology. (For interpretation of the references to colour in this figure, the reader is referred to the web version of this article) 


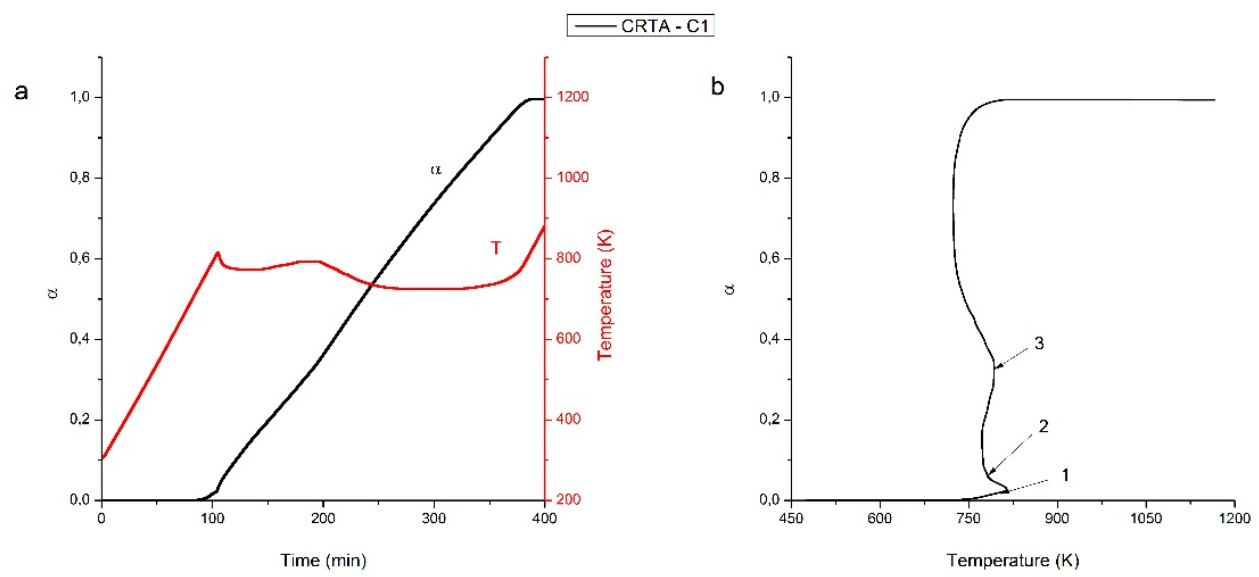

483

484

485

486

487

488

Figure 3. a) Evolution of conversion and temperature against time and b) evolution of conversion against temperature, for the thermal degradation of PEEK $450 G$ (C1) recorded under CRTA conditions. (For interpretation of the references to colour in this figure, the reader is referred to the web version of this article)

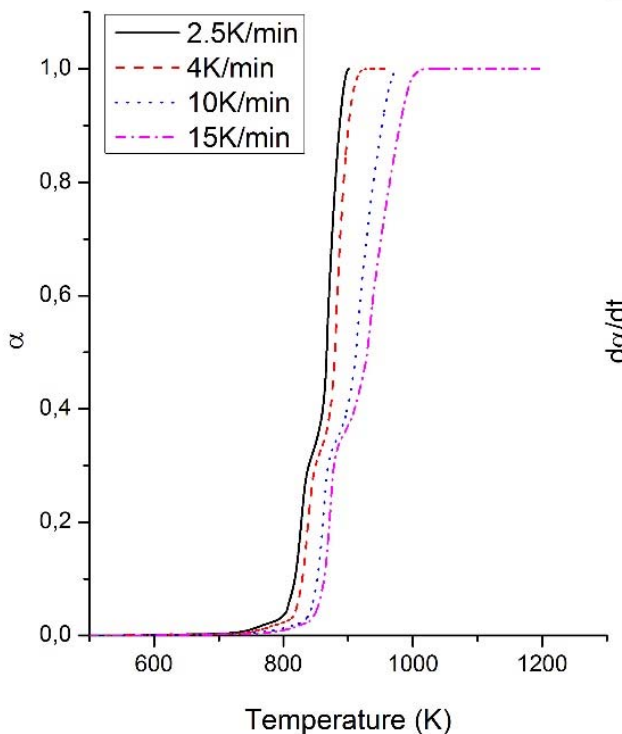

C1

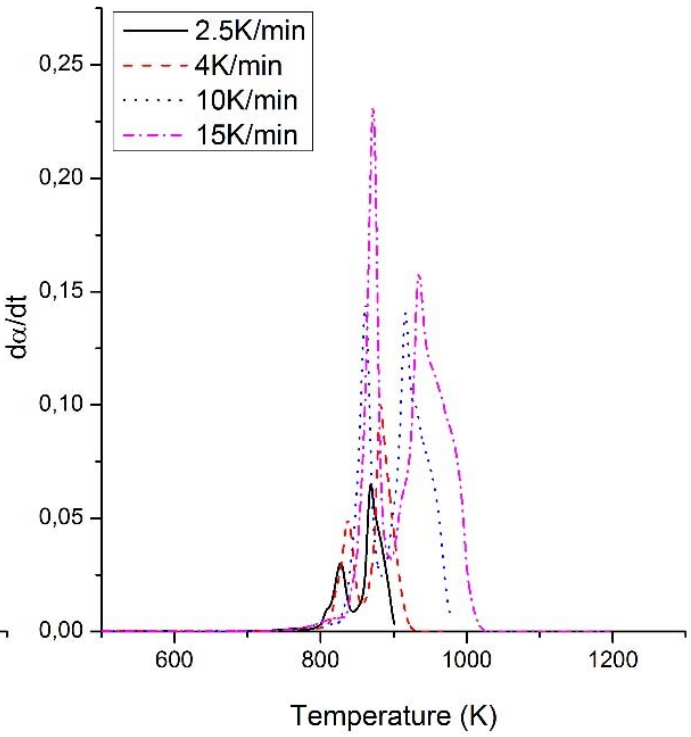

490

Figure 4. TGA experiments for PEEK $450 \mathrm{G}$ in air (C1), performed at 2.5, 4, 10, and $15 \mathrm{~K} / \mathrm{min}$. a) Evolution of conversion with temperature; $b$ ) evolution of reaction rate $(d \alpha / d t)$ with temperature. (For interpretation of the references to colour in this figure, the reader is referred to the web version of this article) 


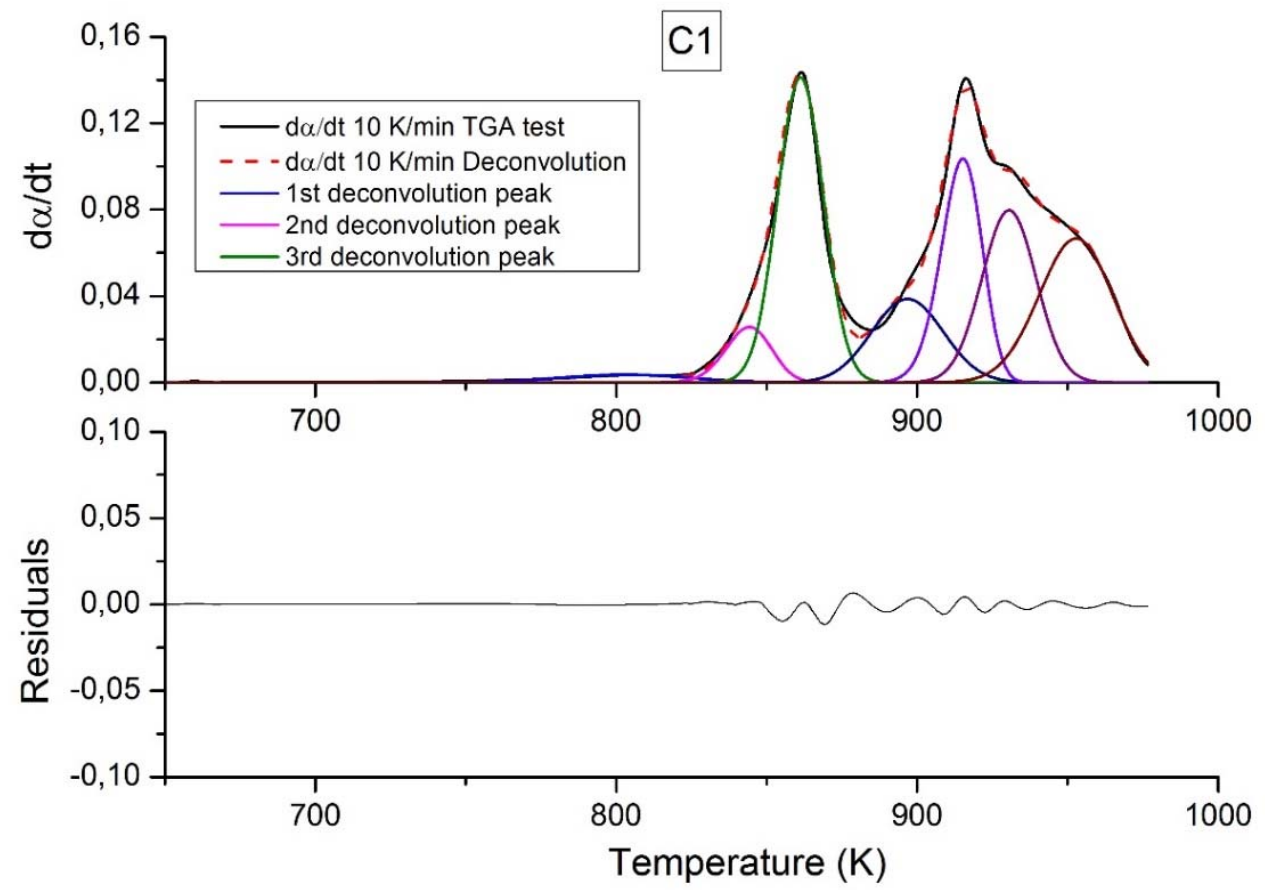

494

Figure 5. Deconvolution of the whole curve of reaction rate for the experiment performed at $10 \mathrm{~K} / \mathrm{min}$ for PEEK450G (C1) (For interpretation of the references to colour in this figure, the reader is referred to the web version of this article)
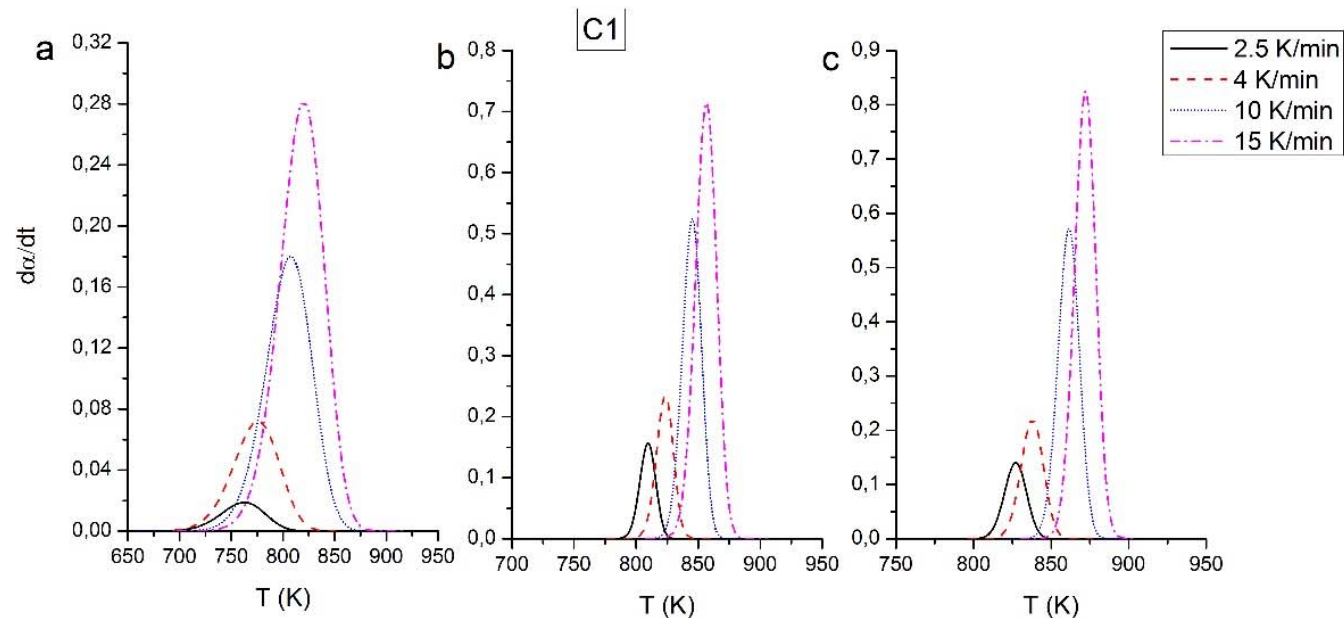

Figure 6. Deconvoluted peaks for the thermal degradation of PEEK in air recorded at 2.5, 4, 10, and $15 \mathrm{~K} / \mathrm{min}$ for a) $1^{\text {st }}$ degradation stage (up to $2 \%$ ), b) $2^{\text {nd }}$ degradation stage (up to $8 \%$ ), and c) $3^{\text {rd }}$ degradation stage (up to $30 \%$ ). (For interpretation of the references to colour in this figure, the reader is referred to the web version of this article) 


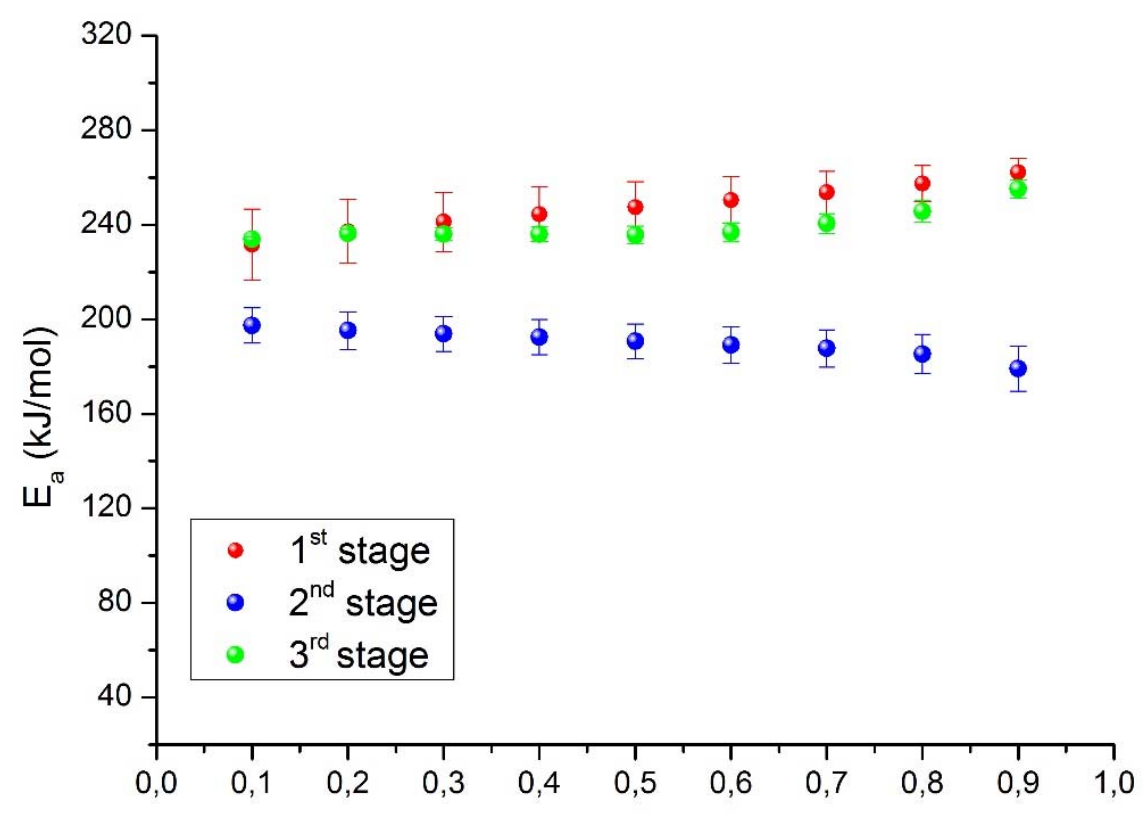

$\alpha$

505 

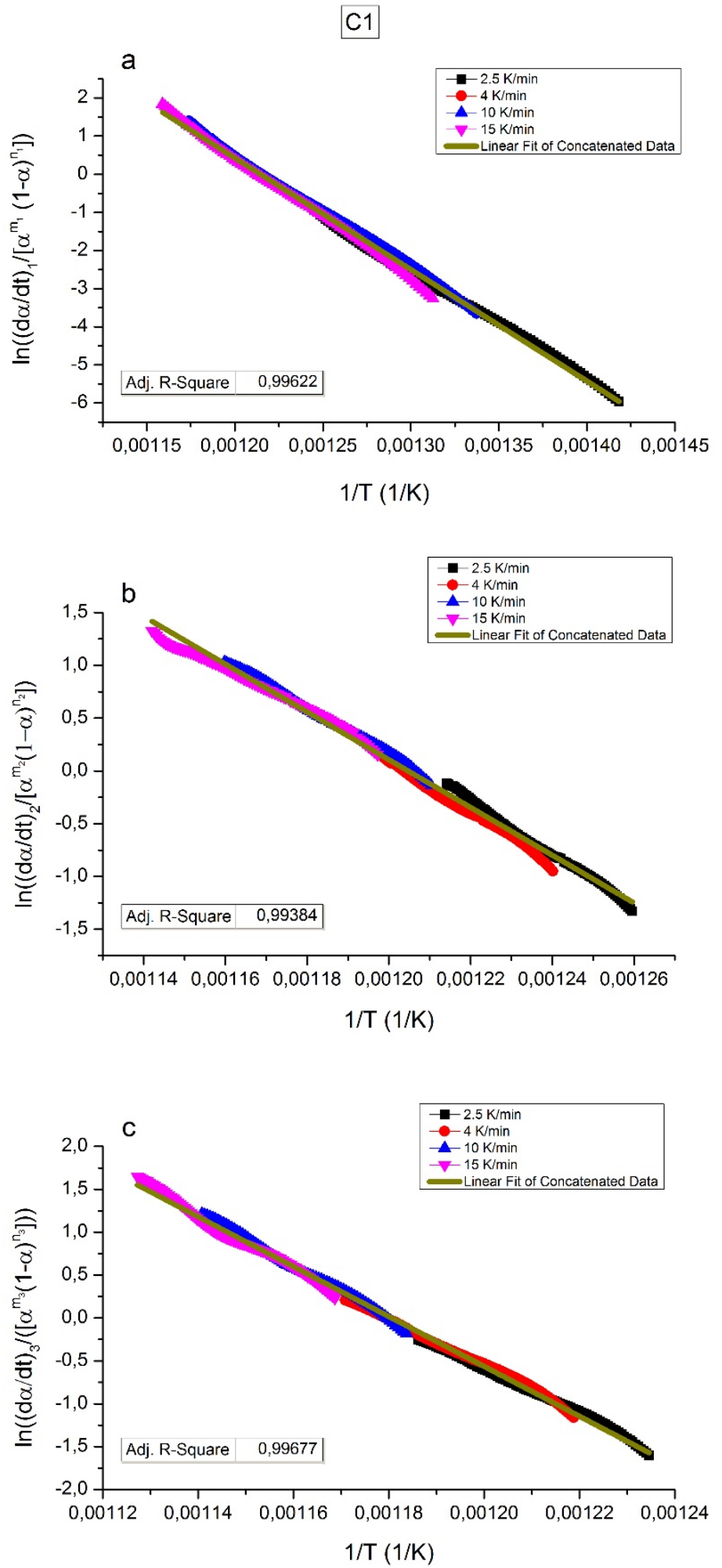

512 Figure 8. Combined kinetic analysis plots for the first three stages of PEEK 450G (C1) degradation in air up to 30\%; a) $5131^{\text {st }}$ stage, b) $2^{\text {nd }}$ stage, c) $3^{\text {rd }}$ stage. (For interpretation of the references to colour in this figure, the reader is referred to the web version of this article) 

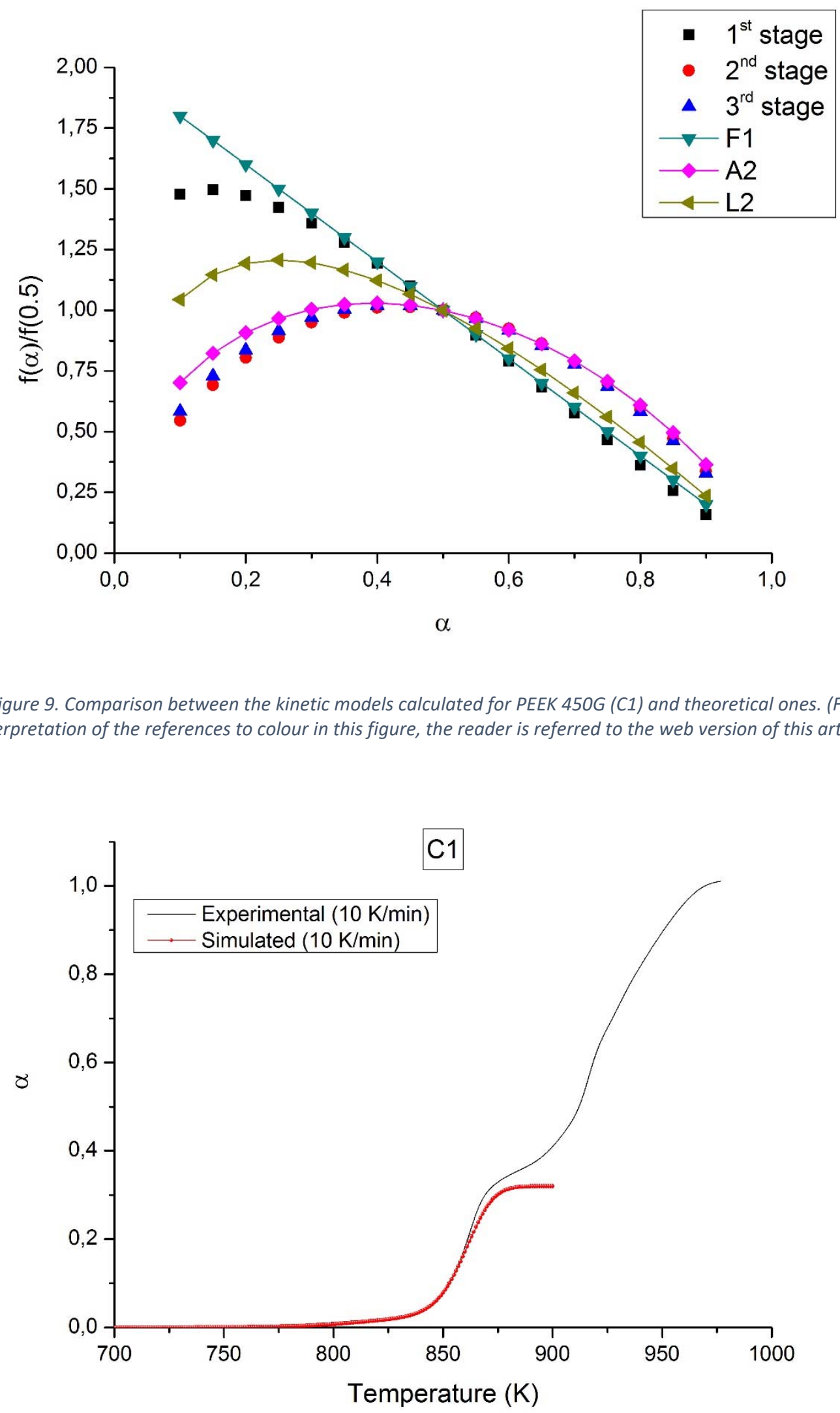

Figure 10. Comparison of the simulated curve for PEEK degradation in air up to $30 \%$ and the experimental curve recorded at $10 \mathrm{~K} / \mathrm{min}$. (For interpretation of the references to colour in this figure, the reader is referred to the web 
a

C1

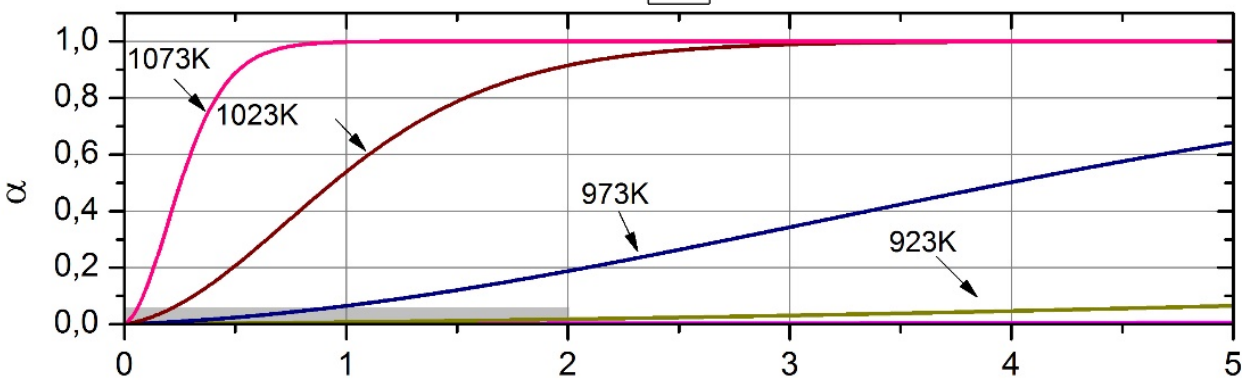

Time (s)

b

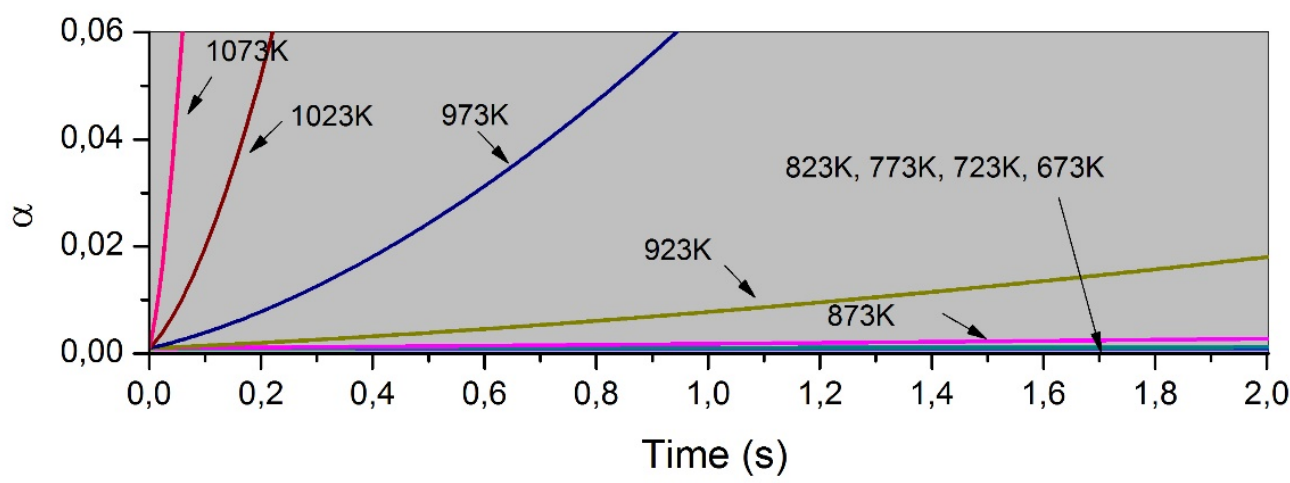

Figure 11. a) Kinetic prediction of PEEK degradation. (Note here that total conversion means the first $30 \%$ of thermal degradation by weight loss) using the kinetic equation (9) obtained from the analysis. Isothermal conditions at different temperatures have been considered, ranging from $673 \mathrm{~K}$ to $1073 \mathrm{~K}$ and lasting $5 \mathrm{~s}, b$ ) Enlarged view of the graph in a), focused on the first $2 \mathrm{~s}$.

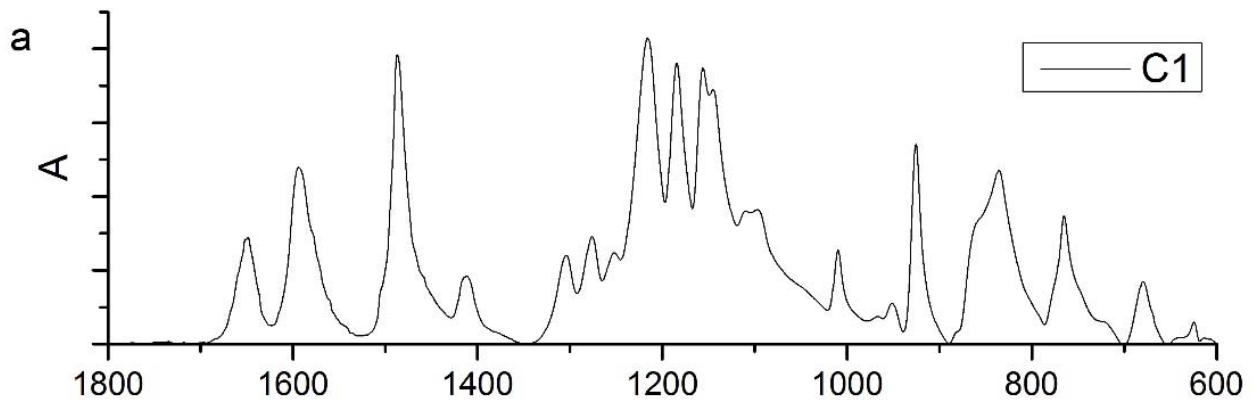

b

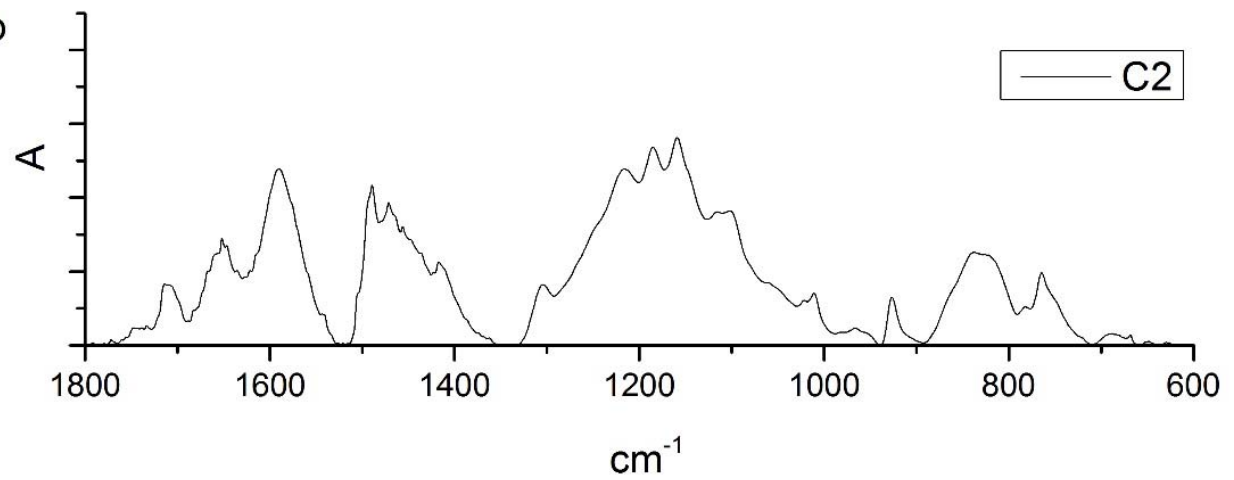


a

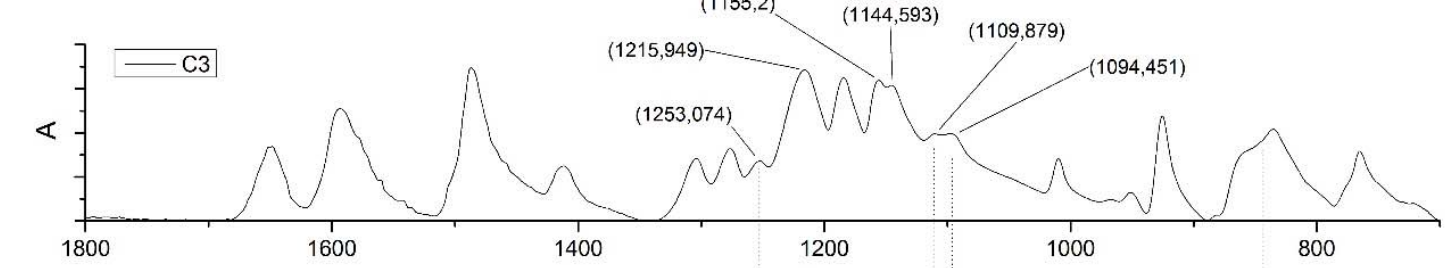

b

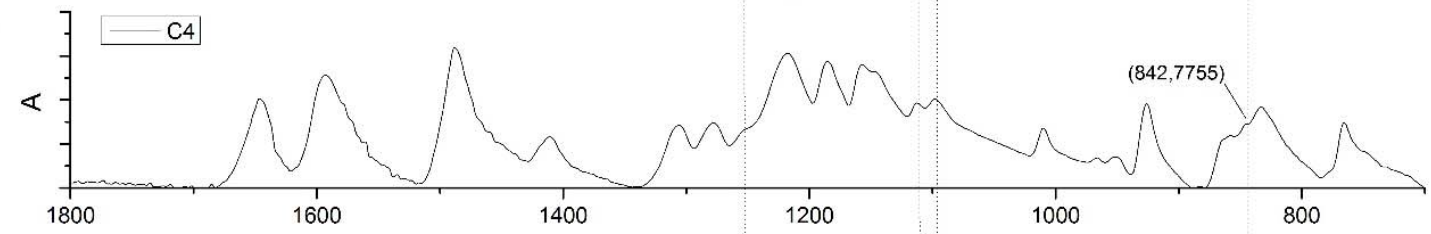

C

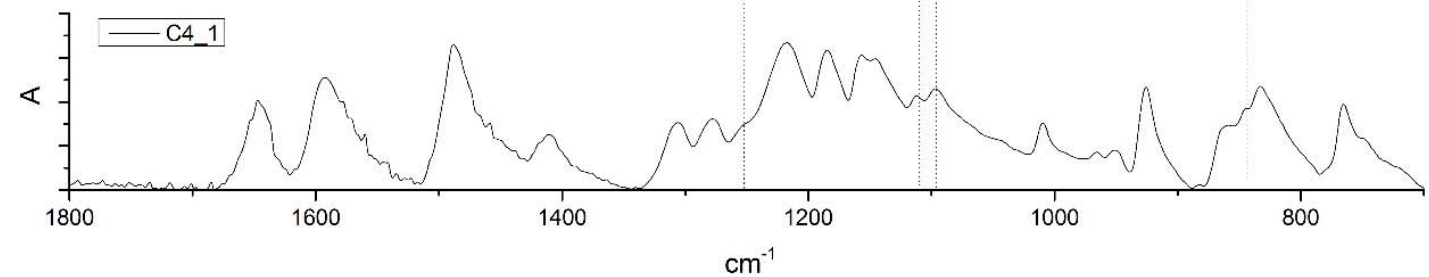

Figure 13. Comparison of ATR-FTIR spectra for a) APC2/AS4 samples as received (C3), b) after laser heating, and c) after laser overheating (increase of temperature of $50 \mathrm{~K}$ ).
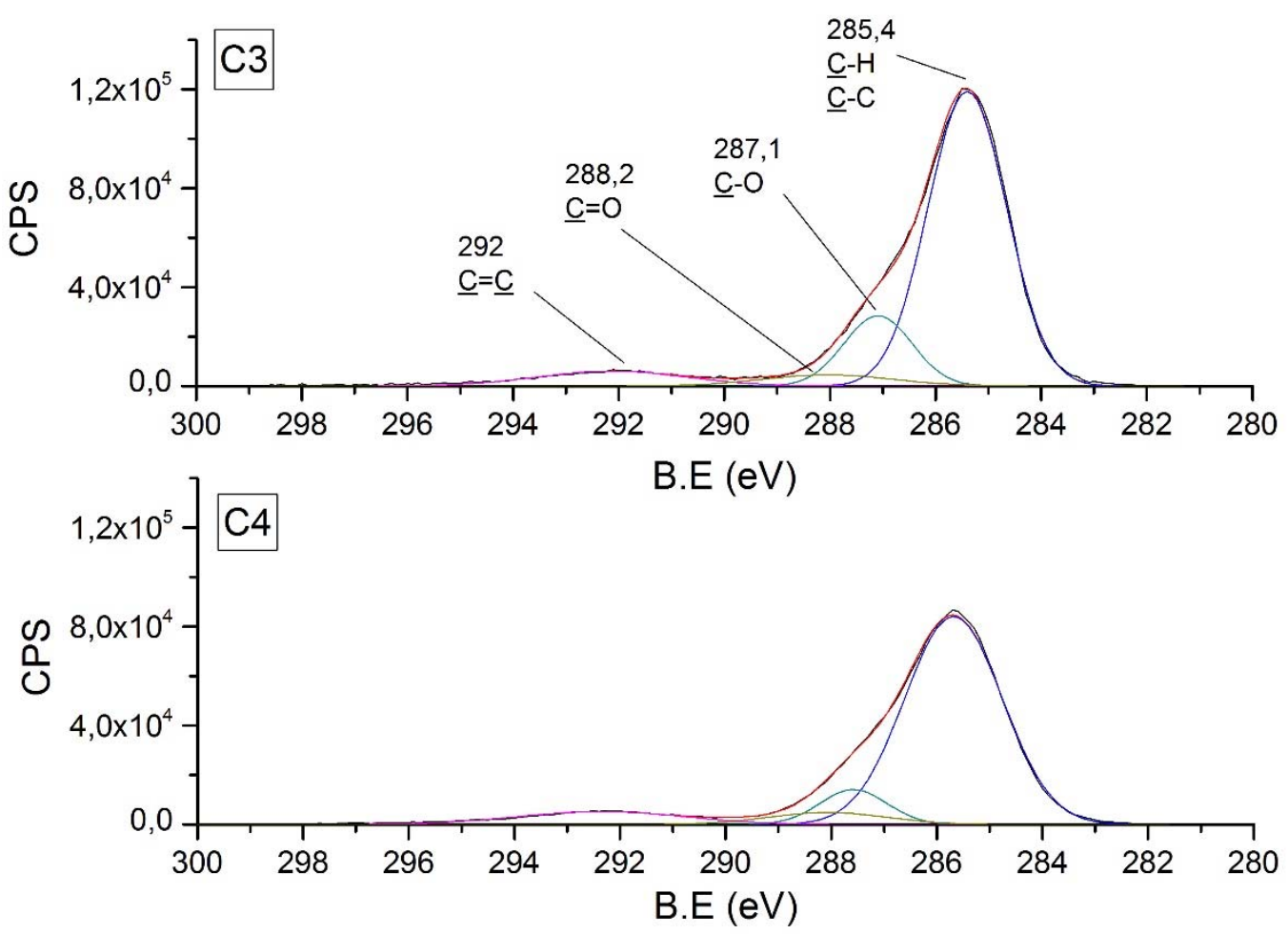

Figure 14. C1s focusing XPS deconvoluted spectra for samples of APC2/AS4 a) as received (C3) and b) after laser irradiation (C4). 


\section{References}

[1] Crosky A, Grant C, Kelly D, Legrand X, Pearce G. Fibre placement processes for composites manufacture. Adv. Compos. Manuf. Process Des., Elsevier; 2015, p. 79-92. doi:10.1016/B978-1-78242-307-2.00004-X.

[2] Schledjewski R, Miaris A. Thermoplastic tape placement by means of diode laser heating. SAMPE ‘09 Spring Symp. Conf. Proc. Baltim., Baltimore: 2009.

[3] Sonmez FO, Akbulut M. Process optimization of tape placement for thermoplastic composites. Compos Part Appl Sci Manuf 2007;38:2013-23. doi:10.1016/j.compositesa.2007.05.003.

[4] Wang EL, Gutowski TG. Laps and gaps in thermoplastic composites processing. Compos Manuf 1991;2:69-78.

[5] Pistor CM, Yardimci MA, Güçeri SI. On-line consolidation of thermoplastic composites using laser scanning. Compos Part Appl Sci Manuf 1999;30:1149-1157.

[6] Mallick V. Thermoplastic composite based processing technologies for high performance turbomachinery components. Compos Part Appl Sci Manuf 2001;32:1167-1173.

[7] Heider D, Piovoso MJ, Gillespie JW. A neural network model-based open-loop optimization for the automated thermoplastic composite tow-placement system. Compos Part Appl Sci Manuf 2003;34:791-9. doi:10.1016/S1359-835X(03)00120-9.

[8] Comer AJ, Ray D, Obande WO, Jones D, Lyons J, Rosca I, et al. Mechanical characterisation of carbon fibre-PEEK manufactured by laser-assisted automated-tapeplacement and autoclave. Compos Part Appl Sci Manuf 2015;69:10-20. doi:10.1016/j.compositesa.2014.10.003.

[9] Grogan DM, Ó Brádaigh CM, McGarry JP, Leen SB. Damage and permeability in tapelaid thermoplastic composite cryogenic tanks. Compos Part Appl Sci Manuf 2015;78:390402. doi:10.1016/j.compositesa.2015.08.037.

[10] Grouve WJB, Warnet LL, Rietman B, Akkerman R. On the weld strength of in situ tape placed reinforcements on weave reinforced structures. Compos Part Appl Sci Manuf 2012;43:1530-6. doi:10.1016/j.compositesa.2012.04.010.

[11] Grouve WJB, Warnet LL, Rietman B, Visser HA, Akkerman R. Optimization of the tape placement process parameters for carbon-PPS composites. Compos Part Appl Sci Manuf 2013;50:44-53. doi:10.1016/j.compositesa.2013.03.003.

[12] Dai SC, Ye L. Characteristics of CF/PEI tape winding process with on-line consolidation. Compos Part Appl Sci Manuf 2002;33:1227-38.

[13] Bourban P-E, Bernet N, Zanetto J-E, M $\backslash$ a anson J-AE. Material phenomena controlling rapid processing of thermoplastic composites. Compos Part Appl Sci Manuf 2001;32:1045-1057.

[14] Schaefer PM, Gierszewski D, Kollmannsberger A, Zaremba S, Drechsler K. Analysis and improved process response prediction of laser- assisted automated tape placement with PA-6/carbon tapes using Design of Experiments and numerical simulations. Compos Part Appl Sci Manuf 2017;96:137-46. doi:10.1016/j.compositesa.2017.02.008.

[15] Fink JK, Thomas S, P. M. V, editors. Handbook of engineering and specialty thermoplastics. Hoboken : Salem, Mass: Wiley; Scrivener; 2010.

[16] Day M, Sally D, Wiles DM. Thermal degradation of poly (aryl-ether-ether-ketone): Experimental evaluation of crosslinking reactions. J Appl Polym Sci 1990;40:1615-1625.

[17] Nicodeau C. Modélisation du soudage en continu de composites à matrice thermoplastique. Doctoral dissertation. ENSAM, 2005.

[18] Flake C. Campbell Jr (Ed.). Manufacturing processes for advanced composites. ISBN 185617-415-8. Oxford: Elsevier; 2004.

[19] Modi D, Comer A, O’Higgins RM, McCarthy MA. Thermoplastic composites: in-situ consolidation or in-situ welding? Proc. 19th Int. Conf. Compos. Mater. ICCM 19 Montr. Can., vol. 28, 2013.

[20] Stokes-Griffin CM, Compston P. The effect of processing temperature and placement rate on the short beam strength of carbon fibre-PEEK manufactured using a laser tape 
placement process. Compos Part Appl Sci Manuf 2015;78:274-83. doi:10.1016/j.compositesa.2015.08.008.

[21] Yao F, Zheng J, Qi M, Wang W, Qi Z. The thermal decomposition kinetics of poly (etherether-ketone)(PEEK) and its carbon fiber composite. Thermochim Acta 1991;183:91-97.

[22] Nam J-D, Seferis JC. Generalized composite degradation kinetics for polymeric systems under isothermal and nonisothermal conditions. J Polym Sci Part B Polym Phys 1992;30:455-463.

[23] Day M, Suprunchuk T, Cooney JD, Wiles DM. Thermal degradation of poly (aryl-etherether-ketone)(PEEK): A differential scanning calorimetry study. J Appl Polym Sci 1988;36:1097-1106.

[24] Day M, Cooney JD, Wiles DM. The thermal degradation of poly (aryl - ether-etherketone)(PEEK) as monitored by pyrolysis - GC/MS and TG/MS. J Anal Appl Pyrolysis 1990;18:163-173.

[25] Perng LH, Tsai CJ, Ling YC. Mechanism and kinetic modelling of PEEK pyrolysis by TG/MS. Polymer 1999;40:7321-7329.

[26] Tsai CJ, Perng LH, Ling YC. A study of thermal degradation of poly (aryl-ether-etherketone) using stepwise pyrolysis/gas chromatography/mass spectrometry. Rapid Commun Mass Spectrom 1997;11:1987-95.

[27] Hache F, Delichatsios M, Fateh T, Zhang J. Comparison of methods for thermal analysis: Application to PEEK and a composite PEEK+CF. J Fire Sci 2015;33:232-46. doi:10.1177/0734904115584154.

[28] Day M, Cooney JD, Wiles DM. The kinetics of the oxidattve degradation of poly(arylether-ether-ketone) (PEEK). Thermochim Acta 1989;147:189-97. doi:10.1016/00406031(89)85174-3.

[29] Khan MA, Mitschang P, Schledjewski R. Identification of some optimal parameters to achieve higher laminate quality through tape placement process. Adv Polym Technol 2010;29:98-111. doi:10.1002/adv.20177.

[30] Kim J, Lee WI, Tsai SW. Modeling of mechanical property degradation by short-term aging at high temperatures. Compos Part B Eng 2002;33:531-543.

[31] Vyazovkin S, Burnham AK, Criado JM, Pérez-Maqueda LA, Popescu C, Sbirrazzuoli N. ICTAC Kinetics Committee recommendations for performing kinetic computations on thermal analysis data. Thermochim Acta 2011;520:1-19. doi:10.1016/j.tca.2011.03.034.

[32] Soudais Y, Moga L, Blazek J, Lemort F. Comparative study of pyrolytic decomposition of polymers alone or in EVA/PS, EVA/PVC and EVA/cellulose mixtures. J Anal Appl Pyrolysis 2007;80:36-52. doi:10.1016/j.jaap.2006.12.033.

[33] Criado JM, Sánchez-Jiménez PE, Pérez-Maqueda LA. Critical study of the isoconversional methods of kinetic analysis. J Therm Anal Calorim 2008;92:199-203. doi:10.1007/s10973-007-8763-7.

[34] Perejón A, Sánchez-Jiménez PE, Criado JM, Pérez-Maqueda LA. Kinetic Analysis of Complex Solid-State Reactions. A New Deconvolution Procedure. J Phys Chem B 2011;115:1780-91. doi:10.1021/jp110895z.

[35] Koga N, Goshi Y, Yamada S, Pérez-Maqueda LA. Kinetic approach to partially overlapped thermal decomposition processes: Co-precipitated zinc carbonates. J Therm Anal Calorim 2013;111:1463-74. doi:10.1007/s10973-012-2500-6.

[36] García-Garrido C, Sánchez-Jiménez PE, Pérez-Maqueda LA, Perejón A, Criado JM. Combined TGA-MS kinetic analysis of multistep processes. Thermal decomposition and ceramification of polysilazane and polysiloxane preceramic polymers. Phys Chem Chem Phys 2016;18:29348-29360.

[37] Sánchez-Jiménez PE, Pérez-Maqueda LA, Perejón A, Criado JM. Combined kinetic analysis of thermal degradation of polymeric materials under any thermal pathway. Polym Degrad Stab 2009;94:2079-85. doi:10.1016/j.polymdegradstab.2009.07.006.

[38] Pérez-Maqueda LA, Criado JM, Sánchez-Jiménez PE. Combined Kinetic Analysis of Solid-State Reactions: A Powerful Tool for the Simultaneous Determination of Kinetic Parameters and the Kinetic Model without Previous Assumptions on the Reaction Mechanism. J Phys Chem A 2006;110:12456-62. doi:10.1021/jp064792g. 
[39] Carrasco F, Pérez-Maqueda LA, Santana OO, Maspoch ML. Enhanced general analytical equation for the kinetics of the thermal degradation of poly(lactic acid)/montmorillonite nanocomposites driven by random scission. Polym Degrad Stab 2014;101:52-9. doi:10.1016/j.polymdegradstab.2014.01.014.

[40] Criado JM, Pérez-Maqueda LA, Koga N. Sample Controlled Thermal Analysis (SCTA) as a Promising Tool for Kinetic Characterization of Solid-State Reaction and Controlled Material Synthesis. In: Šesták J, Hubík P, Mareš JJ, editors. Therm. Phys. Therm. Anal., vol. 11, Cham: Springer International Publishing; 2017, p. 11-43. doi:10.1007/978-3-31945899-1_2.

[41] Pérez-Maqueda LA, Criado JM, Sánchez-Jiménez PE, Perejón A. Kinetic studies in solid state reactions by sample-controlled methods and advanced analysis procedures. J Therm Anal Calorim 2013;113:1447-53. doi:10.1007/s10973-013-3114-3.

[42] Perejón A, Sánchez-Jiménez PE, Criado JM, Pérez-Maqueda LA. A Promising approach to the kinetics of crystallization processes: The sample controlled thermal analysis. J Am Ceram Soc 2017;100:1125-33. doi:10.1111/jace.14604.

[43] Perejón A, Pérez-Maqueda LA, Sánchez-Jiménez PE, Criado JM, Murafa N, Subrt J. Constant rate thermal analysis of a dehydrogenation reaction. RSC Adv 2016;6:81454-60. doi:10.1039/C6RA10157G.

[44] Kuroda S, Terauchi K, Nogami K, Mita I. Degradation of aromatic polymers-I. Rates of crosslinking and chain scission during thermal degradation of several soluble aromatic polymers. Eur Polym J 1989;25:1-7.

[45] Beyler CL, Hirschler MM. Thermal decomposition of polymers. SFPE Handb Fire Prot Eng 2002;2:111-31.

[46] McLauchlin AR, Ghita OR, Savage L. Studies on the reprocessability of poly (ether ether ketone)(PEEK). J Mater Process Technol 2014;214:75-80.

[47] Cuadri AA, Martín-Alfonso JE. The effect of thermal and thermo-oxidative degradation conditions on rheological, chemical and thermal properties of HDPE. Polym Degrad Stab 2017;141:11-8.

[48] Filippone G, Carroccio SC, Mendichi R, Gioiella L, Dintcheva NT, Gambarotti C. Timeresolved rheology as a tool to monitor the progress of polymer degradation in the melt state - Part I: Thermal and thermo-oxidative degradation of polyamide 11. Polymer 2015;72:134-41. doi:10.1016/j.polymer.2015.06.059.

[49] Salehiyan R, Malwela T, Ray SS. Thermo-oxidative degradation study of melt-processed polyethylene and its blend with polyamide using time-resolved rheometry. Polym Degrad Stab 2017;139:130-7. doi:10.1016/j.polymdegradstab.2017.04.009.

[50] Regnier G, Nicodeau C, Verdu J, Cinquin J, Chinesta F. A multi-physic and multi-scale approach to model the continuous welding of thermoplastic matrix composites. ICCM Int. Conf. Compos. Mater., 2007.

[51] Pérez-Maqueda LA, Criado JM, Subrt J, Real C. Synthesis of acicular hematite catalysts with tailored porosity. Catal Lett 1999;60:151-156.

[52] Sánchez-Jiménez PE, Pérez-Maqueda LA, Crespo-Amorós JE, López J, Perejón A, Criado JM. Quantitative Characterization of Multicomponent Polymers by Sample-Controlled Thermal Analysis. Anal Chem 2010;82:8875-80. doi:10.1021/ac101651g.

[53] Sánchez-Jiménez PE, Pérez-Maqueda LA, Perejón A, Criado JM. Constant rate thermal analysis for thermal stability studies of polymers. Polym Degrad Stab 2011;96:974-81. doi:10.1016/j.polymdegradstab.2011.01.027.

[54] Yan Q-L, Zeman S, Svoboda R, Elbeih A. Thermodynamic properties, decomposition kinetics and reaction models of BCHMX and its Formex bonded explosive. Thermochim Acta 2012;547:150-60. doi:10.1016/j.tca.2012.08.018.

[55] Day M, Cooney JD, Wiles DM. The thermal stability of poly (aryl-ether-ether-ketone) as assessed by thermogravimetry. J Appl Polym Sci 1989;38:323-337.

[56] Cole KC, Casella IG. Fourier transform infra-red spectroscopic study of thermal degradation in poly(ether ether ketone)-carbon composites. Polymer 1993;34:740-5. doi:10.1016/0032-3861(93)90357-G. 
[57] Bayerl T, Brzeski M, Martinez-Tafalla M, Schledjewski R, Mitschang P. Thermal degradation analysis of short-time heated polymers. J Thermoplast Compos Mater 2015;28:390-414. doi:10.1177/0892705713486122.

[58] Hesse M, Meier H, Zeeh B, Álvarez RM, Fernández AH, Kretzer MS. Métodos espectroscópicos en química orgánica. ISBN 84-7738-522-X. Madrid: Síntesis; 1999.

[59] Dolo G, Férec J, Cartié D, Grohens Y, Ausias G. Model for thermal degradation of carbon fiber filled poly(ether ether ketone). Polym Degrad Stab 2017;143:20-5. doi:10.1016/j.polymdegradstab.2017.06.006.

[60] Wagner CD. Handbook of x-ray photoelectron spectroscopy: a reference book of standard data for use in x-ray photoelectron spectroscopy. Physical Electronics Division, PerkinElmer Corp.; 1979. 